\title{
Correspondence
}

To the Editors,

\section{Renal function in IUGR neonates}

Sri Lanka Journal of Child Health, 2017; 46(3): 300-301

DOI: http://dx.doi.org/10.4038/sljch.v46i3.8342

(Key words: Renal function, IUGR, neonate)

We read with much interest the article by Makmur $\mathrm{Sitepu}^{1}$ in the June 2017 issue of your journal. We would like to make a few comments, clarification of which is expected to benefit the general readers of the journal.

The main study group in this paper is the newborns having being diagnosed with IUGR (Intra-uterine growth restriction) during the 28-36 weeks of gestation. But firstly, author did not mention the criteria used for diagnosis of IUGR in this study! Secondly, the antenatal diagnosis of IUGR being ultrasound (USG) based it is very important to know what criteria were used (conventional vs. Doppler vs. multiple parameters) for diagnosis, who performed these ultrasounds and also whether there are multiple persons performing $\mathrm{it}^{2}$. This is important to ensure diagnostic accuracy and uniformity.

Though it is mentioned that case and control groups were matched for gestational age but mean gestational age of the neonate in the two groups is also not mentioned. A mean birth weight of 2,952.5 $\mathrm{g}$ in the neonates with IUGR is a bit surprising as it is expected that many neonates with IUGR would be having low birth weight (birth weight $<2500 \mathrm{~g}$ ).

The author also did not mention presence of any recognised cause of IUGR (maternal, placental or fetal) as some of the known causes of IUGR (such as congenital cytomegalovirus infection) may also have led to proteinuria in the neonate 3 .

There is no mention of any exclusion criteria; this makes one wonder whether neonates with congenital anomalies and sick neonates were also included. This is important as the sickness level was found to have a bearing on the urinary excretion of protein and creatinine $^{4}$.

The main variables measured in the study were urine albumin, creatinine and blood cystatin C. But no information is provided regarding the methods used for detection of these parameters. It is important as the values also depend on the method of measurement ${ }^{5}$. 
was then excluded from the study, but if IUGR remained with fetal weight $<10$ percentile based on normogram Hadlock or $\mathrm{HC} / \mathrm{AC}$ ratio $>1.1$ the baby was included in the study.

- It was my own ultrasound examination, in addition to the biometric examination. I also examined the volume of the kidneys with the VOCAL technique (not yet published) with the smaller IUGR fetal volume hypothesis. Since the number of nephrons were fewer, the measurement was performed at 36 weeks because this is the final period of nephrogenesis. When abnormalities were found in the kidney, the case were then removed from the study.

- After birth, if the weight was less than $2500 \mathrm{~g}$, the case was also removed from the study. This means that the IUGR that occurs is only up to 36 weeks and the baby is born with a weight of more than $2500 \mathrm{~g}$. This is the novelty of this study, since babies born are more than $2500 \mathrm{~g}$ they also cannot be separated from the fetal programming effect.

- On day 7 after birth (average age of birth was 38.75 weeks) the babies' urinary albumin content was measured with colorimetry, creatinine method of enzymatic colorimetry, cystatin $\mathrm{C}$ by applying immunonephelometry method

\section{Makmur Sitepu}

Head of Maternal Fetal Medicine, H. Adam Malik Hospital, Medan, Indonesia 